\title{
Perforation Characteristics of Metal Target plate subjected to PELE
}

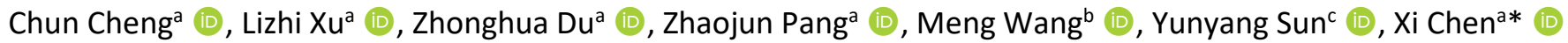 \\ a School of Mechanical Engineering, Nanjing University of Science and Technology, Nanjing 210094, China. Email: xiangchun893@163.com, \\ xulznjust@163.com, duzhonghua@aliyun.com, pangzj@njust.edu.cn, chenxi202@aliyun.com
}

b College of Equipment Engineering, Shenyang Ligong University, Shenyang 110159, China. Email: Wangm2050@163.com

c Nanjing Research Institute of Inner Mongolia North Heavy Industry Group Co., Ltd, Nanjing 210094, China. Email: 1043581933@qq.com

* Corresponding author

http://dx.doi.org/10.1590/1679-78256027

\begin{abstract}
The perforation tests of 45 \# steel target plate and 2A12 aluminium alloy target plate by PELE (the Penetrator with Lateral Efficiency) were carried out in this paper to study the perforation failure characteristics of metal target plate. The macroscopic morphology of perforation on the target plate and the plug was observed, and the perforation wall was cut and polished to observe the distribution and trend of the cracks in the perforation wall by scanning electron microscopy (SEM) and metallographic microscopy. The magnitude and direction of the force produced by PELE on the target during penetration were calculated by numerical simulation. The experimental and numerical results show that, the perforation failure of metal target plate by PELE is different from the ductile perforation by conical-nosed projectile and the punching failure by flat-nosed projectile. The longitudinal cross section of the perforation is funnel-shaped and the shape of the plug is like a circular truncated cone. In the process of penetrating the target plate, the expansion of the filling causes the jacket to exert a force with a certain angle to the direction of projectile movement, which is the main reason for the funnel-shaped perforation and the circular truncated cone shaped plug.
\end{abstract}

\section{Keywords}

metal target plate; PELE(the Penetrator with Lateral Efficiency) ; perforation

\section{Graphical Abstract}

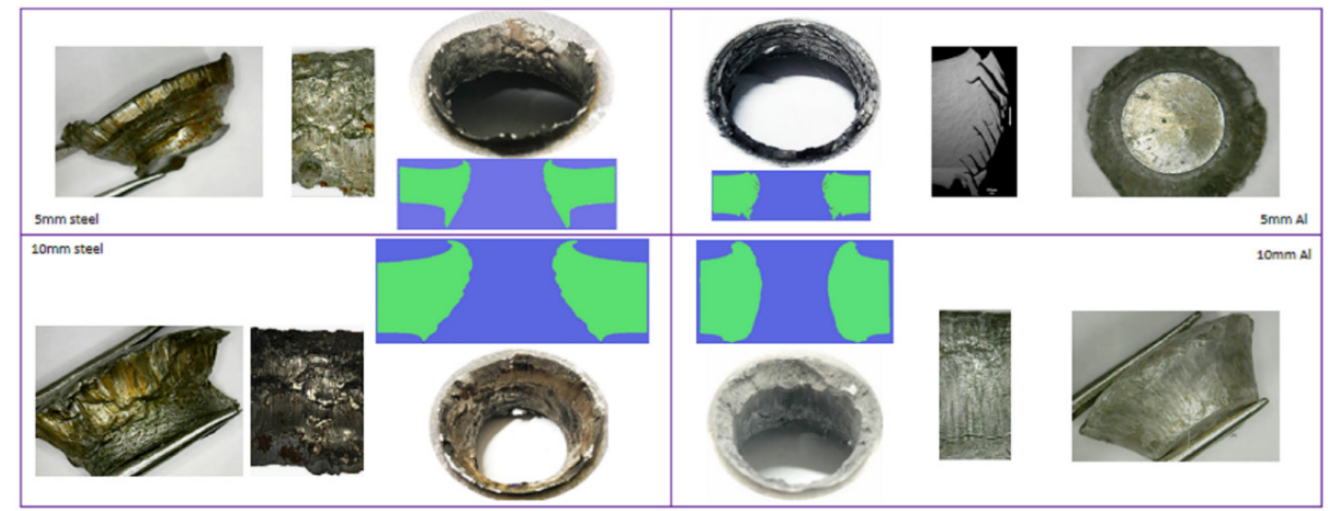

Received: March 13, 2020. In Revised Form: March 24, 2020. Accepted: April 28, 2020. Available online: May 04, 2020. 


\section{INTRODUCTION}

The study of penetration failure of metal structural plates under impact loading has always been an important research topic in the field of impact dynamics (Rodríguez-Martínez et al., 2013; Masri, 2015). Experiments and numerical calculations on the penetration of flat-nosed, ball-nosed and conical-nosed projectiles with a diameter of $20 \mathrm{~mm}$ to the steel plate with a thickness of $12 \mathrm{~mm}$ were carried out by Børvik and his co-workers (Børvik et al., 2002a, 2002b). They found that for flat-nosed projectiles, the finite plastic deformation of the target plate appears outside the local shear zone, but for cone-nosed projectile, the plastic deformation near the perforation on the target plate is quite larger. The damage form of cone-nosed projectile to target plate is ductile perforation enlargement, while that of flat-nosed projectile is punching. Børvik et al. (2003) also carried out experiments, theoretical and numerical studies on flat-nosed projectiles impacting Weldox 460 E steel plates of different thickness at different velocities. It is found that with the increase of the thickness of the target plate, the overall deformation of the target plate decreases and the back bulge of the plug increases. In addition to the projectile breaking when the thickness of the target plate is $25 \mathrm{~mm}$ and $30 \mathrm{~mm}$, the perforation on the target plate is regular and smooth, the plug is smooth cylindrical with a bulge behind it, and the shear band is observed on the side surface on the plug. When the thickness of the target plate is relative thin, the thickness of the plug is almost the same as that of the target plate under the ballistic limit condition, so there is almost no plastic compression and transverse material flow before the plug is fully formed. Shear is the main failure mode. When the thickness of the target plate is larger, the difference between the thickness of the plug and the thickness of the target plate decreases linearly with the increase of the thickness of the target plate. At the same time, for the target plate with the same thickness, the thickness of the plug decreases with the increase of the impact velocity. The diameter of the plug is almost the same as that of the head of the final projectile. Dolinski and Ritte (2015) carried out the test of 4340 steel projectile with a diameter of $20 \mathrm{~mm}$ impacting RHA (Rolled Homogeneous Armor) plate with a thickness of $23 \mathrm{~mm}$. When the impact velocity was $1400 \mathrm{~m} / \mathrm{s}$, the failure mode of target plate was adiabatic shear punching failure. Cylindrical plugs were obtained. The average diameter of the plugs was $20.9 \sim 26.2 \mathrm{~mm}$, and the average thickness of the plugs was $22.2 \mathrm{~mm}$. Dey et al. (2004) compared the influence of the strength of the target plate on the perforation of steel plate by projectile. For Weldox $460 \mathrm{E}$ steel plate, the back diameter of the plugs is slightly larger than the front diameter of the plugs, while for Weldox 700E and Weldox 900E steel plates, the back diameter of the plugs is smaller than the front diameter of the plugs. With the increase of target strength, the thickness of the plug increases. The perforation process of ductile metal target plates impacted by rigid flat-nosed projectiles was theoretically analyzed and simulated by Chen and his co-workers (Chen et al., 2009). Their research results validate the hypothesis of constant shear stress in the process of punching and piercing, and prove that the dynamic cavity expansion model is also suitable for describing the impact of flat-nosed projectiles on thick metal plates. A large number of experiments and numerical calculations have shown that the failure mode of flat-nosed projectile on metal target plate is mostly shear punching failure.

PELE is a new type of projectile which composed of high density cylindrical jacket and low density filling inside (Jimmy, 2015; Paulus and Schirm, 2006). After penetrated the target plate, the radial binding of the target plate to the jacket disappears, and the damaged jacket breaks up and the fragments disperse further under the radial force produced by the expansion of the filling (Cheng et al., 2019). Many scholars have studied the influence of material and structure of projectile on the fragments s produced by PELE, as well as the velocity and statistical rule of fragments (Zhu et al., 2009, 2010; Fan et al., 2017; Ding et al., 2018), but one one has studied the damage mode of this kind of projectile to metal target plate.

In this paper, the perforation failure characteristics of flat-nosed PELE on metal target plate are studied. When the projectile impacts the target plate, the head of the filling undergoes rapid plastic expansion deformation due to the huge pressure produced by impact. The plastic expansion deformation of the filling produces a radial force on the projectile jacket, which far exceeds the yield strength of the jacket, so that the jacket can generate radial expansion even under the restraint of the target plate. In the process of punching, the target plate is not only subjected to the axial impact force by the projectile, but also subjected to the radial force from the jacket. Therefore, the failure mode of target plate subjected to PELE is not just shear failure, which is different to the failure by flat-nosed rod projectile. During the study, the PELE was fired by ballistic gun at different velocities to impact 45\#steel plate and 2A12 aluminium alloy plates. The thickness of the target plate was $5 \mathrm{~mm}$ and $10 \mathrm{~mm}$, respectively. The water tank was used to collect the plugs. 
Macroscopic and microscopic observation of perforation on the target plate and numerical simulation were carried out to study the perforation failure characteristics of PELE on metal target plate.

\section{EXPERIMENT}

\subsection{Experimental configuration}

In the experiment, $25 \mathrm{~mm}$ caliber ballistic gun was used as launching device. The metal target plate was fixed on the target frame $6 \mathrm{~m}$ away from the muzzle. There were two kinds of target sizes, $200 \mathrm{~mm} \times 200 \mathrm{~mm} \times 5 \mathrm{~mm}$ and $200 \mathrm{~mm} \times 200 \mathrm{~mm} \times 10 \mathrm{~mm}$. Two velocity paper target plates with on and off aluminum foil were arranged at $0.5 \mathrm{~m}$ in front of the target plate to measure the impact velocity of the projectile during each experiment. A water tank of $0.6 \mathrm{~m} \times 0.6 \mathrm{~m} \times 0.6 \mathrm{~m}$ was placed at $0.4 \mathrm{~m}$ behind the target plate to collect the fragments produced by the impact of the projectile and the plug formed from the target plate. In order to avoid deformation of the plug, the polystyrene foam $(0.6 \mathrm{~m} \times 0.6 \mathrm{~m} \times 0.6 \mathrm{~m})$ was used on the side facing the muzzle. Plastic film was laid in the tank in order to prevent the water tank from leaking. The jacket is $38.1 \mathrm{~mm}$ in length, $12.7 \mathrm{~mm}$ in diameter and the filling is $34.1 \mathrm{~mm}$ in length and $9 \mathrm{~mm}$ in diameter. The experimental set-up and the structure of the projectile are shown in Figure 1(a). Pictures of the projectiles in Figure 1(b) shows that the assembled projectile is composed of two parts, the sabot and the projectile. The sabot consists of two aluminium alloy clasps and one nylon thread ring which has a tail skirt with a diameter slightly larger than the caliber of the gun. In the process of launching, the nylon thread ring plays the role of not only assembling and fixing the aluminium alloy clasps, but also sealing the propellant gas. After flying out of the muzzle, the aluminium alloy clasps are separated because of the air resistance and the loss of the restraint of the gun barrel.

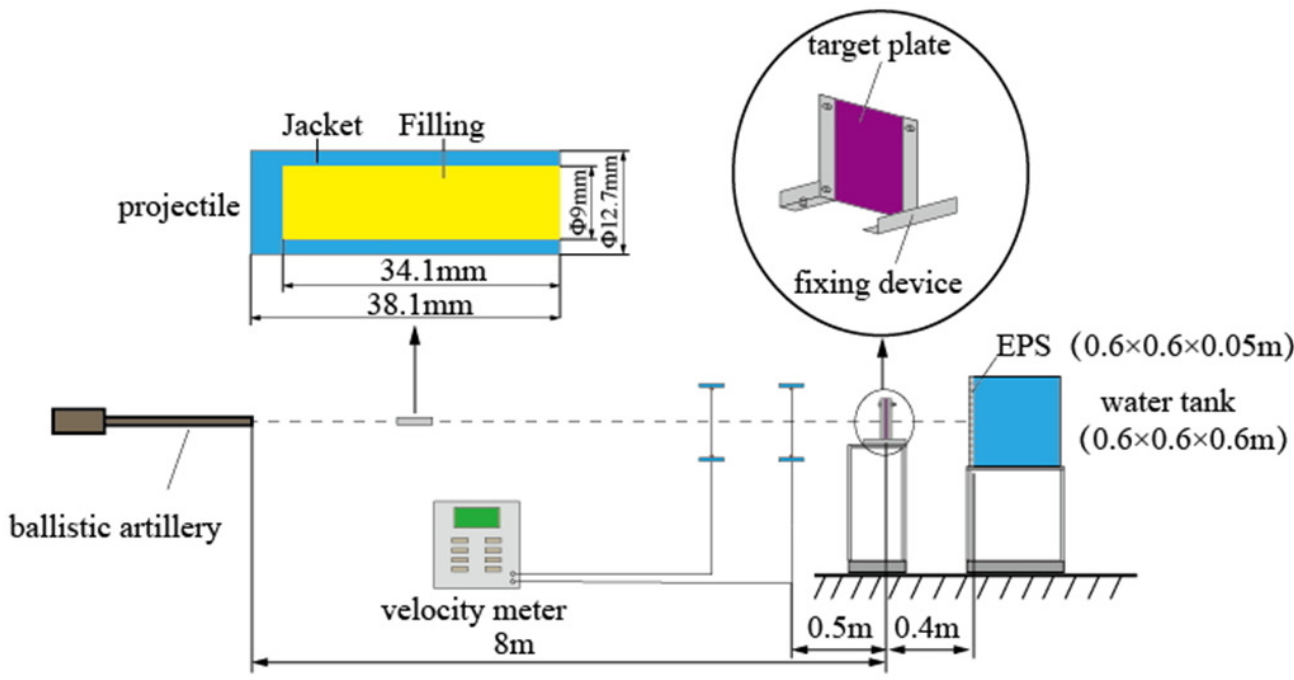

(a) Experimental set-up and the structure of the projectile

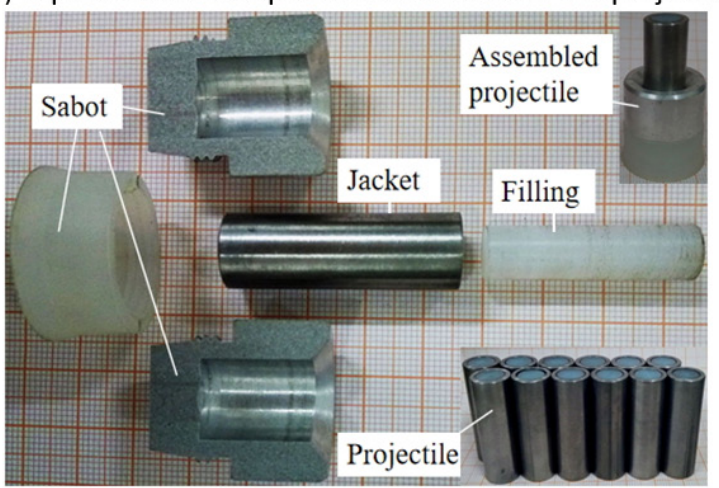

(b) Projectiles

Figure 1 Experimental set-up, projectiles used for impact experiment 


\subsection{Projectile and target material}

The test projectile consists of tungsten alloy jacket and nylon filling. The materials of target plate are 45 \# steel and 2A12 aluminium alloy. The main material properties of tungsten alloy, nylon, 45 \# steel and 2A12 aluminium alloy are shown in Table 1 (Cheng et al., 2019; Tang et al., 2006).

Table 1. Main material properties of tungsten alloy, nylon, 45 \# steel and $2 \mathrm{~A} 12$ aluminium alloy

\begin{tabular}{ccccc}
\hline & tungsten alloy & nylon & 45\#steel & 2A12 aluminium alloy \\
\hline Density (g/cm3) & 17.8 & 1.14 & 7.83 & 2.77 \\
Poisson's ratio & 0.33 & 0.4 & 0.3 & 0.33 \\
Elastic modulus (GPa) & 360 & 20.3 & 210 & 71.7 \\
Yield strength(MPa) & 1350 & 70 & 497 & 400 \\
\hline
\end{tabular}

\subsection{Experimental results and discussion}

In this study, nine projectiles were launched. The impact velocity of the projectile was about $1000 \mathrm{~m} / \mathrm{s}$. The mass of the jackets and fillings, impact velocity, material and thickness of the target plates are shown in Table 2.

Table 2. Experimental data

\begin{tabular}{|c|c|c|c|c|}
\hline \multicolumn{2}{|c|}{ Projectile } & \multirow{2}{*}{ - Impact velocity(m/s) } & \multicolumn{2}{|c|}{ Target plate } \\
\hline Mass of jacket(g) & Mass of Filling (g) & & Material & Thickness(mm) \\
\hline 46.00 & 2.31 & 990.2 & 45\#steel & 5 \\
\hline 45.82 & 2.32 & 998.2 & 45\#steel & 5 \\
\hline 45.70 & 2.25 & 1015.3 & 45\#steel & 10 \\
\hline 45.58 & 2.32 & 996.2 & 45\#steel & 10 \\
\hline 46.00 & 2.28 & 1091 & 45\#steel & 10 \\
\hline 46.08 & 2.32 & 990.4 & $2 \mathrm{~A} 12$ aluminium alloy & 5 \\
\hline 46.24 & 2.28 & 1025.8 & $2 \mathrm{~A} 12$ aluminium alloy & 5 \\
\hline 45.92 & 2.29 & 1007.5 & 2A12 aluminium alloy & 10 \\
\hline 46.06 & 2.30 & 1002.3 & 2A12 aluminium alloy & 10 \\
\hline
\end{tabular}

When the target plate is 45 \# steel plate with a thickness of $5 \mathrm{~mm}$ and the impact velocity of the projectile is $998.2 \mathrm{~m} / \mathrm{s}$, the experimental and numerical results are shown in Figure 2. The plug with approximate the circular truncated cone shape was collected in the test. The diameter of the front end of the plug is about $9.2 \mathrm{~mm}, \mathrm{which}$ is approximately equal to the inner diameter of the projectile jacket. The diameter of the rear end of the plug is about $15.5 \mathrm{~mm}$, which is about 1.22 times the outer diameter of the projectile jacket. The thickness of the plug is $5 \mathrm{~mm}$, which is basically the same as that of the target plate. Combined with the plug obtained by simulation, it can be clearly seen that the rear end of the plug has no obvious bulge but significant flanging, which indicates that the compression effect of the projectile on the target plate lasts very short, and the local shear plays a major role in the perforation process. There are flangings around the perforation on both the front and rear sides of the target plate. The height of rear flanging is $3.40 \mathrm{~mm}$, which is much higher than that of front flanging $(1.33 \mathrm{~mm})$. The front flanging on the target plate is caused by the compression and pushing of local area of target plate by the projectile and the plastic flow appears towards the area where the resistance of the target plate is weaker. The rear flanging on the target plate is due to the necking of the target plate material during the plug formation stage (Arias et al., 2008). The longitudinal cross section of perforation on the target plate is funnel-shaped. The diameter of the front flanging on the target plate is about $15.50 \mathrm{~mm}$, and the diameter of the rear flanging is about $19.20 \mathrm{~mm}$, which are 1.22 and 1.51 times the diameter of the projectile, respectively. It shows that the projectile has obvious perforation enlargement effect on the target plate. Compared with the straight perforation of the ordinary flat-nosed projectile on the target plate, the diameter of the back side of the perforation formed by PELE on the target plate is obviously larger than that of the front side of the the perforation. It can 
also be seen from Figure 2 that the perforation wall of the target plate is bright but has pits, which shows that the projectile has compression and squeezing effect on the perforation wall besides shearing effect on the target plate. In addition, the tensile fracture marks can be clearly observed on the perforation wall near the back of the target plate.

A piece of sample is cut off from the perforation wall of the target plate and polished to be observed by scanning electron microscopy (SEM). The micro-structure pictures observed by SEM are shown in Figure 3 (the direction of white arrow in the figure is the direction of projectile movement). It can be seen from the figure that there are many cracks formed by micro-voids in the range of about $50 \mu \mathrm{m}$ from the perforation wall. These cracks are parallel and the angle between the cracks and the direction of projectile movement is about $13.19^{\circ}$. A large number of micro-voids are distributed in the range of $50 \mu \mathrm{m}$ to $100 \mu \mathrm{m}$ away from the perforation wall. In the process of projectile penetration to the target plate, the huge pressure makes the material of target plate undergo severe plastic deformation, resulting in the breakage of inclusions or second-phase particles in target plate, or the separation of inclusions and matrix interface to form micro-voids, which grow and connect along the direction of shear stress in target plate to form cracks (Ramesh et al., 2015). This indicates that the fracture mode of 45\# steel target plate is ductile fracture. In Figure 3, we can also see that the edge of the perforation is silver-white and uneven. This is because the large amount of heat generated by the impact of the projectile on the target plate can not dissipate immediately, so that the temperature of local area on the target plate increases, resulting in rapid melting of the target plate material at the contact area between the projectile and the target plate. When the projectile penetrates the target plate, the locally melted target plate material cools and solidifies rapidly, forming a white band-like melting fast solidifying layer (Luo et al., 2015).

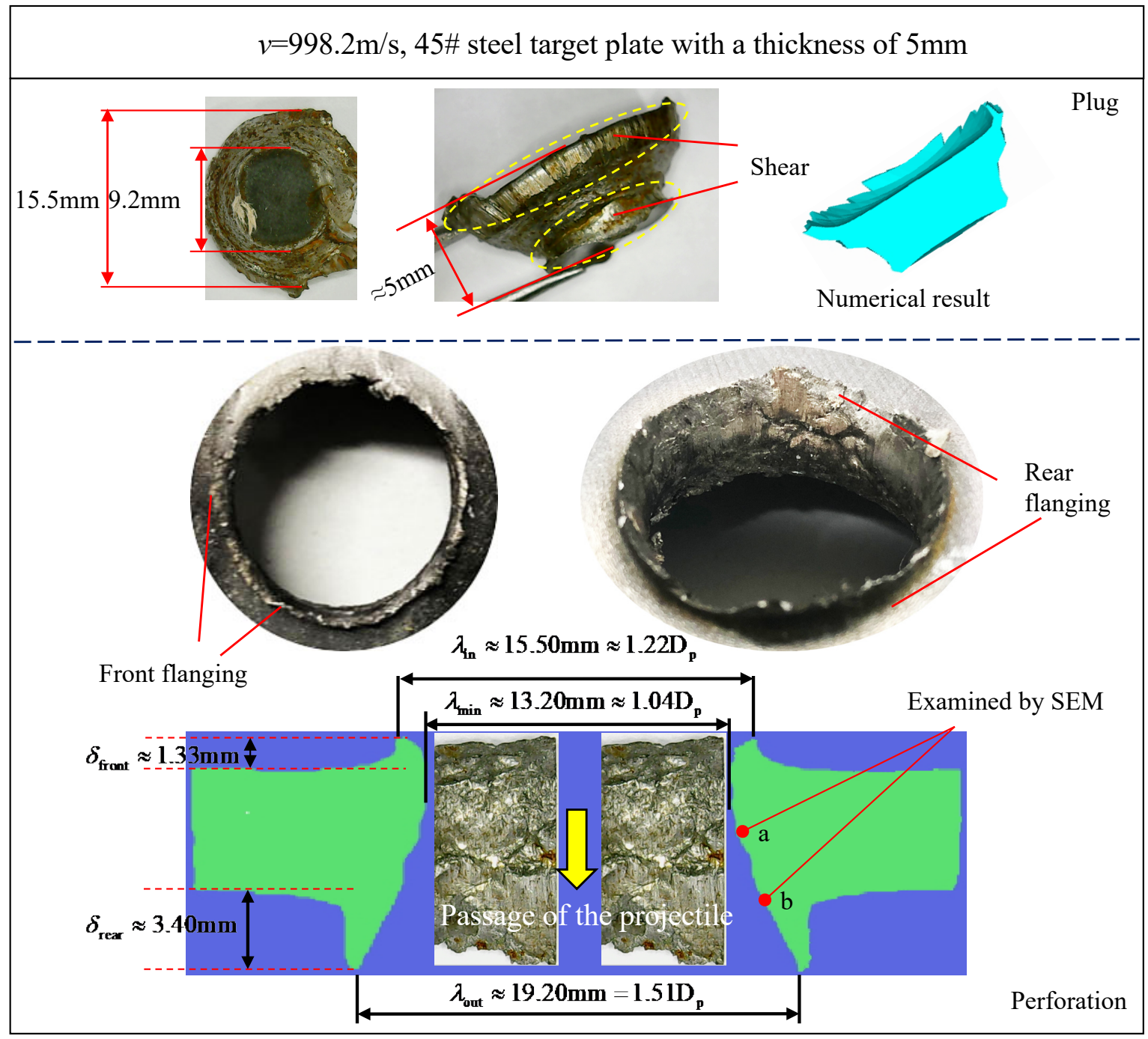

Figure 2 Plug and perforation of $45 \#$ steel target plate with a thickness of $5 \mathrm{~mm}$ 


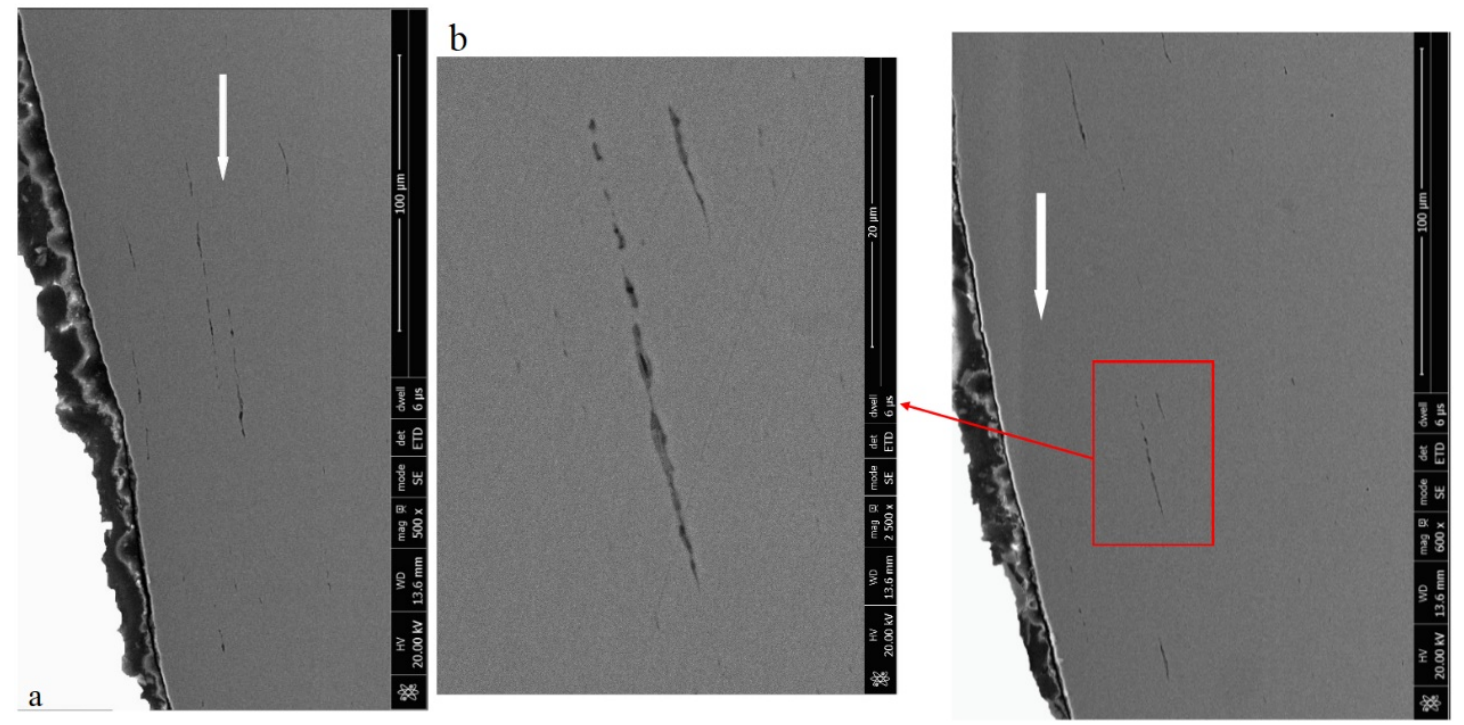

Figure 3 Cracks in the perforation wall observed by SEM

When the target plate is 45 \# steel plate with a thickness of $10 \mathrm{~mm}$ and the impact velocity of the projectile is $1015.3 \mathrm{~m} / \mathrm{s}$, the experimental and numerical results are shown in Figure 4. The plug collected in the test is also approximate the circular truncated cone shape. The diameter of the front end of the plug is about $11.2 \mathrm{~mm}$, which is slightly larger than the inner diameter of the projectile jacket. The diameter of the rear end of the plug is about $21.5 \mathrm{~mm}$, which is about 1.69 times the outer diameter of the projectile jacket. The thickness of the plug is $8.9 \mathrm{~mm}$, which is less than the thickness of the target plate. Combining with the shape of the plug obtained by simulation, we can see that the rear side of the plug has obvious bulge, which indicates that the projectile has obvious compression effect on the target plate besides local shear effect in the process of penetrating the target plate. With the increase of the thickness of the target plate, the plastic flow of the target material under the compression of the projectile increases, and the convexity on the rear side of the target plate reduces the necking in tension. The height of the front flanging on the target plate is about $3.23 \mathrm{~mm}$, the height of the rear flanging is about $1.27 \mathrm{~mm}$, and the height of the front flanging is about 2.54 times of that of the rear flanging, which is different from the flanging of the target plate with a thickness of $5 \mathrm{~mm}$. It indicates that under the premise that the projectile can penetrate the target plate, the larger the thickness of the target plate, the more prominent the role of the projectile in expanding the penetration on the target plate. It can also be seen from the uneven perforation wall of the target plate that the projectile has not only shear effect on the target plate, but also compression and squeezing effect on the perforation wall.

SEM is used to observe the sample cut from the perforation wall. The photograph taken by SEM is shown in Figure 5. The direction indicated by the white arrow in the figure is the direction of the projectile movement. It can be seen that some cracks formed by the connection of micro-voids are paralleled distributed in the perforation wall. The angle between the cracks and the direction of projectile movement is $15.95^{\circ}$. Silver-white melting rapid solidification layer can also be seen at the edge of the perforation. In addition, it can be observed that the deformation and broken tungsten particles adhering to the perforation wall. Among them the large tungsten particles are the deformed, broken and falling tungsten particles form the projectile jacket, which flow to the perforation wall with the melted bonding phase and solidify rapidly. There are also some little broken tungsten particles embedded in the perforation wall when the melting fast solidification layer is formed on the perforation wall. 


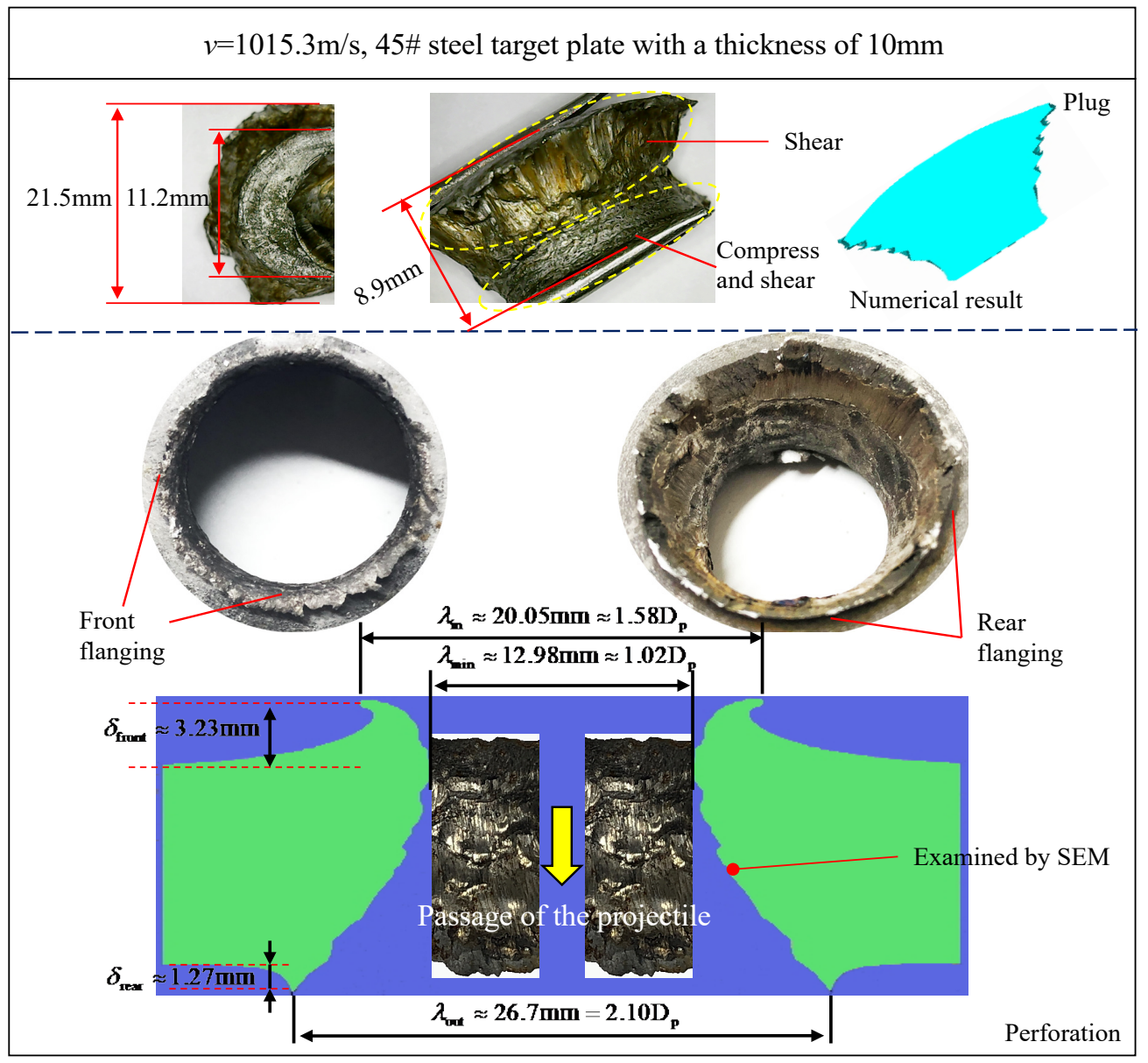

Figure 4 Plug and perforation of $45 \#$ steel target plate with a thickness of $10 \mathrm{~mm}$

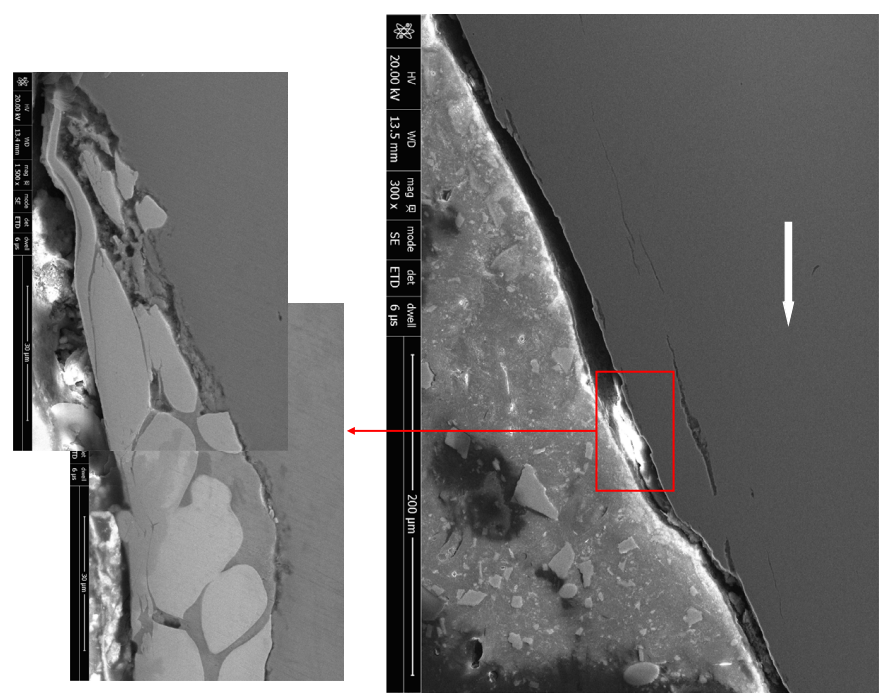

Figure 5 Cracks and tungsten particles on the perforation wall observed by SEM

When the target plate is $2 \mathrm{~A} 12$ aluminium alloy plate with a thickness of $5 \mathrm{~mm}$ and the impact velocity of the projectile is $990.4 \mathrm{~m} / \mathrm{s}$, the experimental and numerical results are shown in Figure 6 . The diameter of the front end of the plug is about $9.1 \mathrm{~mm}$, which is approximately equal to the inner diameter of the projectile jacket. The diameter of the rear end of the plug is about $13.4 \mathrm{~mm}$, which is about 1.06 times the outer diameter of the projectile jacket. The thickness of the plug is about $5 \mathrm{~mm}$, which is basically the same as that of the target plate. The obvious bulge at the rear end of the plug indicates that the compression of the projectile on the target plate during penetration causes the 
plastic deformation of the target plate. The flanging formed by plastic flow of the target plate under compression on the front of the target plate is very small, the height of the flanging is about $0.66 \mathrm{~mm}$, which indicates that the toughness of the target plate is poor and the plastic failure strain of the target plate material is small. There is a ring groove formed by spallation on the back of the target plate and a large number of scaly annular shear bands are distributed on the perforation wall. The diameter of the front flanging on the target plate is about $15.00 \mathrm{~mm}$, the diameter of the back annular groove is about $17 \mathrm{~mm}$, which is 1.18 and 1.34 times the diameter of the projectile, and the diameter of the shear band on the back of the target plate is about $14.32 \mathrm{~mm}$, which is 1.13 times the diameter of the projectile. It indicates that the enlargement effect of the projectile on the target plate is not obvious, and when the thickness of target plate is small, the plastic flow of 2A12 aluminum target plate impacted by PELE is not obvious, and its fracture mode is mainly shear fracture.

The distribution of cracks and shear bands in the perforation wall of the target plate was observed by metallographic microscope as shown in Figure 7. The cracks are distributed parallel, and the angle between the cracks and the direction of projectile movement is about $26.57^{\circ}$. The length of the "large and long" main cracks along the perforation wall decreases gradually from front to back. The number of small cracks on the "scales" decreases from front to back along the perforation wall. The main reason is that in the penetration process, the velocity of the projectile decreases gradually, and the pressure and strain rate of plastic deformation on the contact surface between the target plate and the projectile decreases gradually.

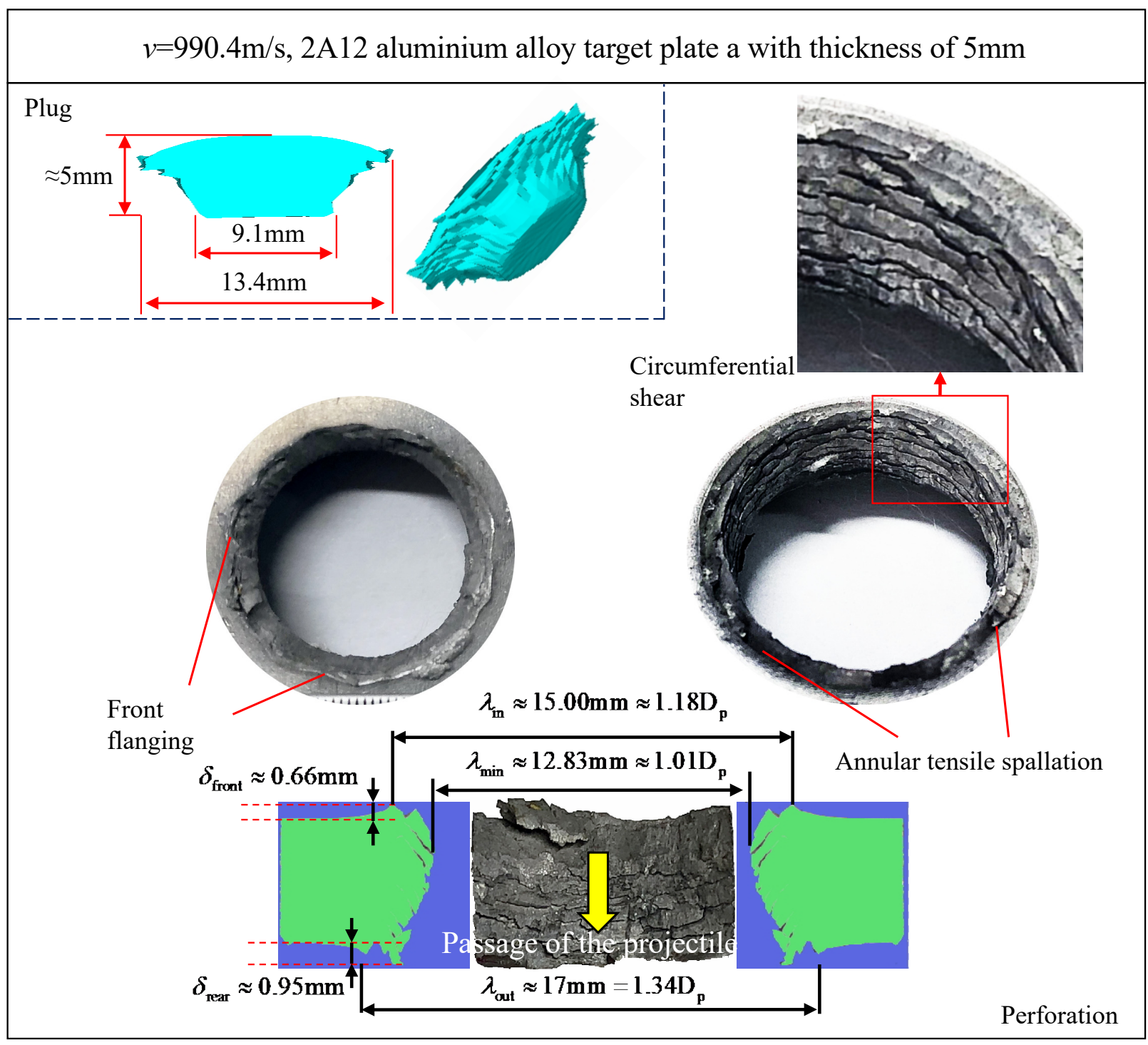

Figure 6 Plug and perforation of 2A12 aluminium alloy target plate with a thickness of $5 \mathrm{~mm}$ 


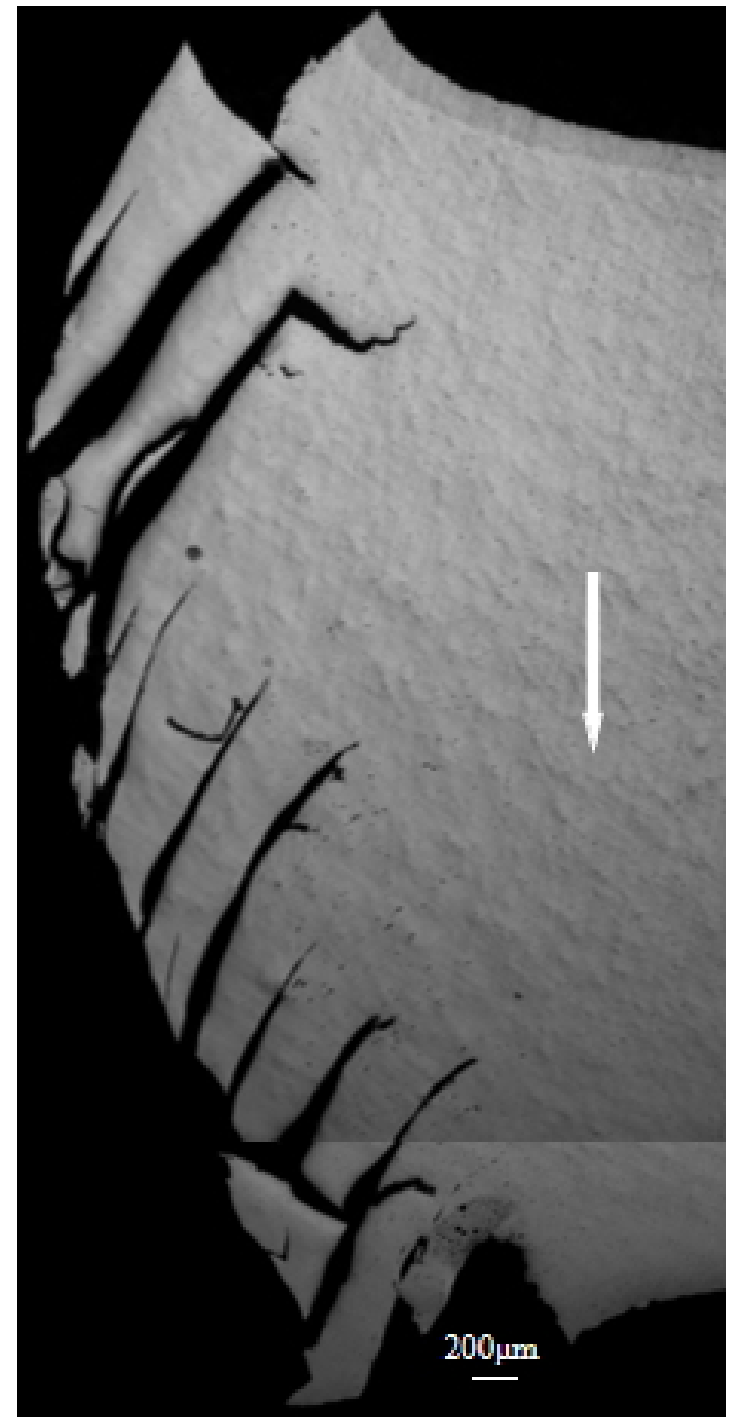

Figure 7 Cracks on the perforation wall observed by metallographic microscopy

When the target plate is $2 \mathrm{~A} 12$ aluminium alloy plate with a thickness of $10 \mathrm{~mm}$ and the impact velocity of the projectile is $1007.5 \mathrm{~m} / \mathrm{s}$, the experimental and numerical results are shown in Figure 8 . The plug is still in the shape of a circular truncated cone. The diameter of the front end of the plug is about $9.6 \mathrm{~mm}$ and that of the rear end is about $17.1 \mathrm{~mm}$. The thickness of the plug is about $8.1 \mathrm{~mm}$, and there is a prominent bulge on the rear side of the plug, which indicates that the plug is obviously compressed. The height of flanging on the front of the target plate is about $2.64 \mathrm{~mm}$, which indicates that there is a large plastic flow on the front of the target plate. The serious collapse on the back of the target plate indicates that the tensile stress wave produced by the projectile impacting the target plate causes a larger spallation on the back of the target plate. The diameter of the front flanging on the target plate is about $20.62 \mathrm{~mm}$, and the diameter of back collapse is about $23 \mathrm{~mm}$, which is 1.62 times and 1.81 times the diameter of the projectile, respectively. This indicates that when the thickness of the $2 \mathrm{~A} 12$ aluminum alloy target plate is relatively large, the front plastic flow will occur evidently, but the tensile failure will happen when the tensile strain is small.

The cracks in the perforation wall observed by SEM are shown in the Figure 9. The length of cracks from the front to the back of the target plate is gradually shortened, the gap between cracks is getting larger and larger, the number of cracks is getting smaller and smaller, and the cracks can not be observed near the back of the target plate. An interesting phenomenon was found when observing the distribution of the cracks. Near the front of the target plate, the angle between the parallel cracks and the direction of projectile movement is approximately an acute angle. At a distance of about $2 \sim 3 \mathrm{~mm}$ from the front of the target plate, the direction of the crack changes. The angle between the cracks and the direction of projectile movement changes to be an obtuse angle. 


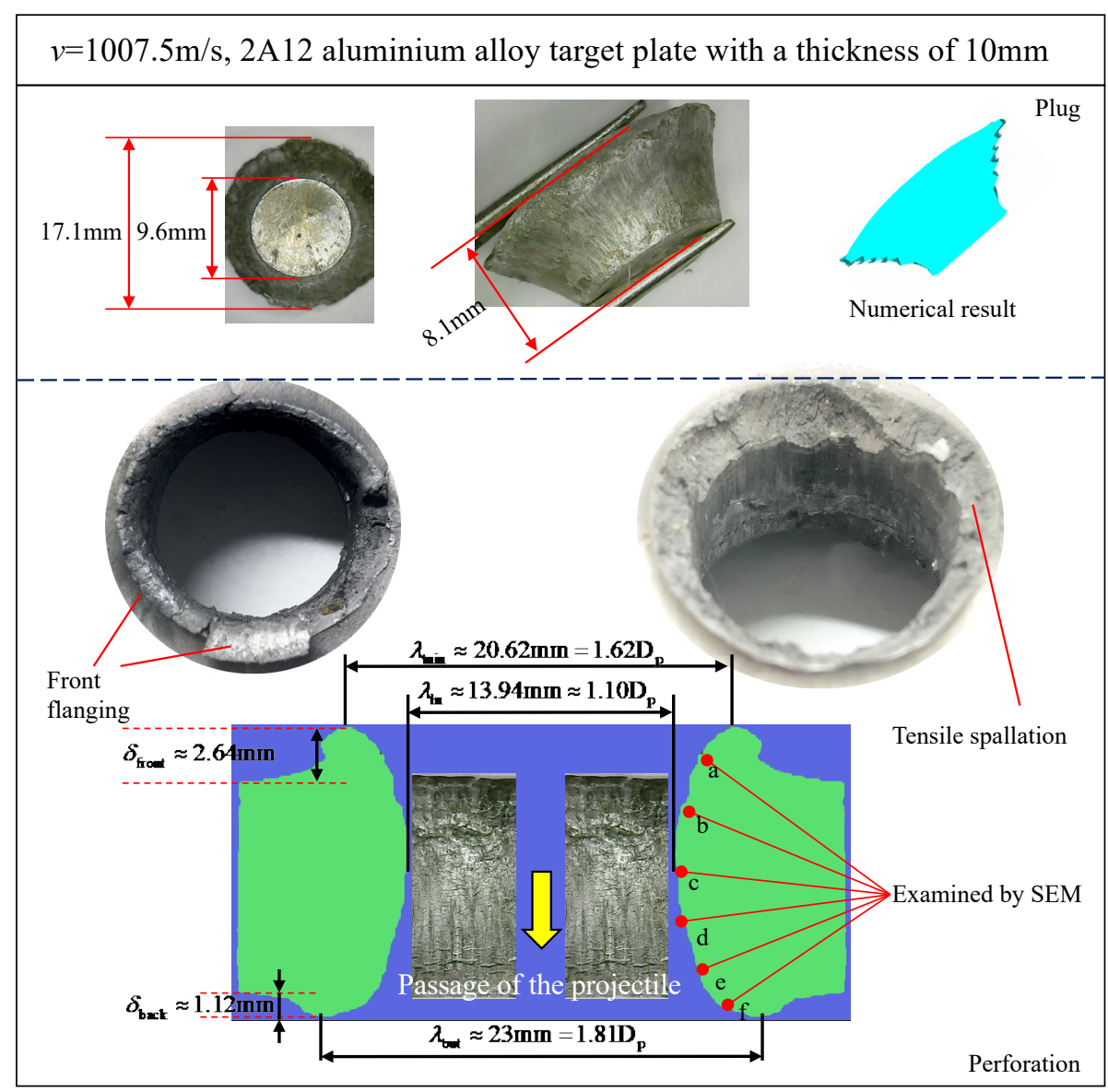

Figure 8 Plug and perforation of 2A12 aluminium alloy target plate with a thickness of $10 \mathrm{~mm}$

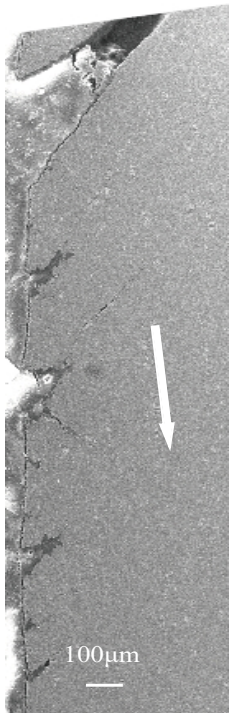

a

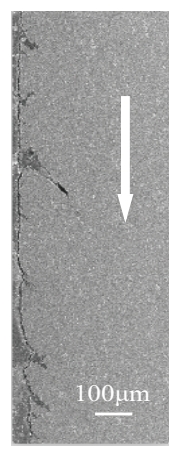

b

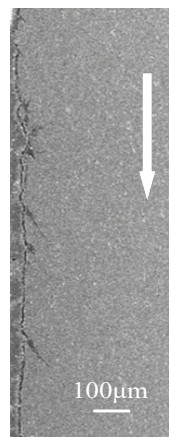

c
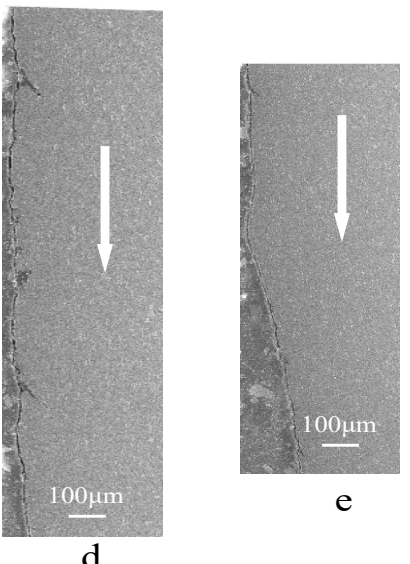

$\mathrm{e}$

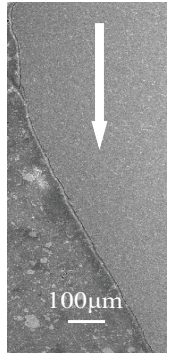

f

Figure 9 Cracks on the perforation wall observed by SEM

The size of the perforation on the target plate and the plug is shown in Table 3. From the data in the table, it can be clearly seen that the longitudinal cross section of the perforation is funnel-shaped and the shape of the plug is like a circular truncated cone. 
Table 3. The size of the perforation on the target plate and the plug

\begin{tabular}{cccccc}
\hline \multirow{2}{*}{ Type of target plate } & \multicolumn{2}{c}{ Perforation on target plate } & & \multicolumn{2}{c}{ Plug } \\
\cline { 2 - 3 } \cline { 5 - 6 } & $\begin{array}{c}\text { Diameter of front end } \\
(\mathbf{m m})\end{array}$ & $\begin{array}{c}\text { Diameter of rear end } \\
(\mathbf{m m})\end{array}$ & $\begin{array}{c}\text { Diameter of front end } \\
(\mathbf{m m})\end{array}$ & $\begin{array}{c}\text { Diameter of rear end } \\
(\mathbf{m m})\end{array}$ \\
\hline 45 steel(5mm) & 15.50 & 19.20 & 9.20 & 15.50 \\
45 steel $(10 \mathrm{~mm})$ & 20.05 & 26.70 & 11.20 & 21.50 \\
2A12 aluminium alloy(5mm) & 15.00 & 17.00 & 9.10 & 13.40 \\
2A12 aluminium alloy $(10 \mathrm{~m})$ & 20.62 & 23.00 & 9.60 & 17.10 \\
\hline
\end{tabular}

\section{NUMERICAL SIMULATION}

\subsection{Numerical model}

When the projectile head impacts the target plate, the propagation distance of shock wave in the filling is assumed to be $x_{1}$, and the pressure on the contact surface between the filing and the target plate is assumed to be:

$$
p_{f}=v_{0} \frac{\rho_{f} U_{f} \rho_{t} U_{t}}{\rho_{f} U_{f}+\rho_{t} U_{t}}
$$

Where $\rho$ represents density and $U$ represents shock wave velocity,subscripts $f$ and $t$ denote filling and target respectively, $v_{0}$ is the impact velocity (Paulus and Schirm, 2006).

According to the propagation law of shock wave in medium, the pressure on wave front and the velocity of wave front decrease exponentially with the increase of propagation distance(Goel et al., 2014). At the displacement $x$ on the filling, the pressure on the shock front is as follows:

$$
p(x)=p_{f}+\alpha e^{-\beta x}
$$

Where $\alpha, \beta$ are coefficients related to shock wave attenuation. After the shock wave, the axial stress at this position is as follows:

$$
\sigma_{\mathrm{X}}(x)=p_{f}+\alpha e^{-\beta x}
$$

The radial stress is:

$$
\sigma_{Y}(x)=\frac{\mu}{1-\mu}\left(p_{f}+\alpha e^{-\beta x}\right)
$$

Where $\mu$ is Poisson's ratio. During the penetration process, the radial expansion of the filling and the impact compression of the jacket itself cause slight radial expansion of the jacket, and micro-cracks occur in the front section of the projectile jacket.

The processes of PELE impacting four kinds of metal target plates ( 45 \# steel plate with a thickness of $5 \mathrm{~mm}$, 45 \# steel plate with a thickness of $10 \mathrm{~mm}, 2 \mathrm{~A} 12$ aluminum alloy plate with a thickness of $5 \mathrm{~mm}$, and $2 \mathrm{~A} 12$ aluminum alloy plate with a thickness of $10 \mathrm{~mm}$,) at a speed of $1000 \mathrm{~m} / \mathrm{s}$ were simulated by using Autodyn numerical code. Smooth particle hydrodynamics (SPH) method was used to simulate the fragmentation process of the jacket. The Johnson-Cook strength model was used to describe the deformation and failure behavior of the jacket in the process of PELE penetrating target plate. Based on the brittle fracture behavior of tungsten alloy, especially high density tungsten alloy under dynamic loading, the tensile principal stress 
failure criterion describing the failure of brittle materials was added to the Johnson-Cook strength model. The fragments have obvious statistical characteristics of probability, and because the fragments are random when the jacket is broken, but the structure and material of the jacket are uniform and the material properties are unique in numerical simulation. Therefore, in order to simulate the random characteristics of the jacket fragmentation, the stochastic failure model based on Mott's theory was introduced to the failure criterion of tensile principal stress. Fixed boundary constraints are set around the target plate. The target plate is seriously plastic deformed and destroyed under the impact of projectile. Therefore, the Johnson-Cook model is also used for the material of the target plate. In order to truly reflect the plugging phenomenon of the target plate, the geometric erosion failure strain was set to 1 for the target plate model in the simulation. The validity of the numerical simulation has been verified in the author's another article (Defence Science Journal, 2019, 69: 591-598.). In order to observe the force on inner wall of the jacket, the pressure at the contact interface between the projectile and the target plate, and better reflect the action mechanism of PELE on the metal target plate, eight observation points are set up on the longitudinal central section of the projectile and the target plate. The numerical model and the position of observation points are shown in Figure 10. On the inner wall of the jacket, 6 observation points are arranged in turn from $5 \mathrm{~mm}$ away from the projectile head. The distance between two adjacent observation points is $5 \mathrm{~mm}$. In addition, an observation point is set at the contact area between the jacket and the target plate named Gauge \#8, and an observation point is also set at the contact point between the filling and the target plate named Gauge \#7.

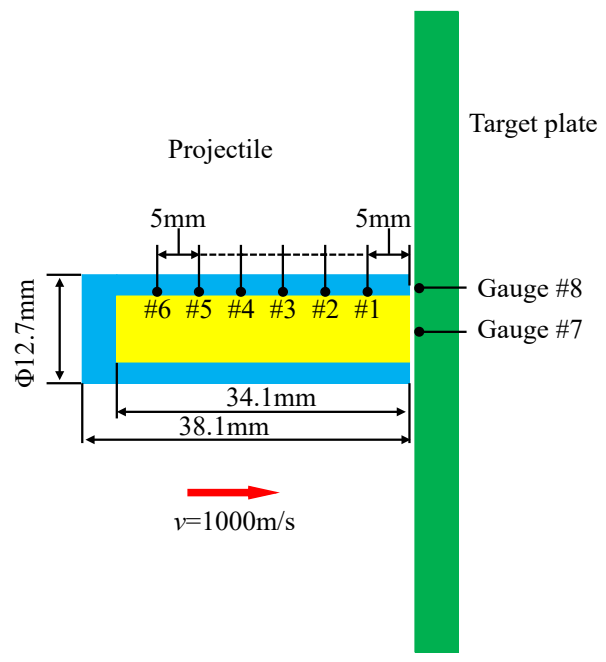

Figure 10 Numerical model and the position of observation points

\subsection{Numerical results and discussion}

The pressure curves at Gauge \#7 and Gauge \#8 are obtained by numerical simulation as shown in Figure 11. It can be seen that the peak pressure at Gauge \#7 is obviously higher than that at Gauge \#8. When the target plate is $45 \#$ steel plate with the thickness of $5 \mathrm{~mm}$ and $10 \mathrm{~mm}$ respectively, the peak pressures at the interface between the jacket and the target plate are $2.61 \times 10^{7} \mathrm{kPa}, 2.75 \times 10^{7} \mathrm{kPa}$ respectively, and the peak pressures at the interface between the filling and the target plate are $9 \times 10^{6} \mathrm{kPa}, 10.14 \times 10^{6} \mathrm{kPa}$ respectively. When the target plate is $2 \mathrm{~A} 12$ aluminium alloy plate with the thickness of $5 \mathrm{~mm}$ and $10 \mathrm{~mm}$ respectively, the peak pressures at the interface between the jacket and the target plate are $1.29 \times 10^{7} \mathrm{kPa}, 1.36 \times 10^{7} \mathrm{kPa}$ respectively, and the peak pressures at the interface between the filling and the target plate are $6 \times 10^{6} \mathrm{kPa}, 6.5 \times 10^{6} \mathrm{kPa}$ respectively. The peak pressure produced by projectile jacket impacting $45 \#$ steel plate is about twice that of projectile jacket impacting 2A12 aluminum alloy plate with the same thickness. The peak pressure produced by projectile filling impacting $45 \#$ steel plate is about 1.5 times that of projectile filling impacting $2 \mathrm{~A} 12$ aluminum alloy plate with the same thickness. For the same material target plate, when the thickness of the target is larger, the peak pressure of the projectile impacting the target plate increases slightly. The forces acting on the inner wall of the projectile jacket are shown in the pressure curves observed at each observation points shown in Figure 12. From the head to the tail of the projectile, the peak pressure of each observation point decreases exponentially. The force acting on the inner wall of the jacket during the impact of projectile on 45 \# steel plate is greater than that acting on the inner wall of the jacket during the impact of projectile on 2A12 aluminum alloy plate. 
For the $45 \#$ steel plate with a thickness of $5 \mathrm{~mm}$, the pressure at Gauge\#1 is about $7.1 \times 10^{6} \mathrm{kPa}$, which is approximated regarded as the radial pressure on the cross section of the jacket head. the pressure at Gauge\#8 is about $7.1 \times 10^{6} \mathrm{kPa}$, which is the axial pressure on the cross section of the jacket head. The angle between the resultant force on the jacket head and the direction of the projectile movement is about $105.22^{\circ}$, that is, the angle between the force of the jacket head on the target plate and the direction of the projectile movement is $15.22^{\circ}$. The angle between the direction of cracks in the perforation wall of target plate and the direction of projectile movement observed by SEM is about $13.19^{\circ}$. Similarly, for $45 \#$ steel plate with a thickness of $10 \mathrm{~mm}$, the angle between the force of the jacket head on the target plate and the direction of the projectile movement is $15.60^{\circ}$. The angle between the direction of cracks in the perforation wall of target plate and the direction of projectile movement observed by SEM is about $15.95^{\circ}$. The direction of the cracks in the perforation wall of the target plate is basically parallel to the action direction of the jacket head on the target plate, which is shown that the cracks in the perforation wall are caused by the shear action of projectile on the target plate. It also illustrates that the certain angle between the shear force of the projectile jacket on the target plate and the direction of the projectile movement leads to the formation of the funnel-shaped perforation and the circular truncated cone shaped plug.

For $2 \mathrm{~A} 12$ aluminium alloy plate with a thickness of $5 \mathrm{~mm}$, The angle between the resultant force on the jacket head and the direction of the projectile movement is about $113.09^{\circ}$, that is, the angle between the force of the jacket head on the target plate and the direction of the projectile movement is $23.09^{\circ}$. The angle between the direction of cracks in the perforation wall of target plate and the direction of projectile movement observed by metallurgical microscope is about $26.57^{\circ}$. It can be seen that the angle between the cracks and the direction of the force of the jacket head on the target plate is $49.66^{\circ}$. For $2 \mathrm{~A} 12$ aluminum alloy target plate with a thickness of $5 \mathrm{~mm}$ impacted by PELE, the cracks in the perforation wall of the target plate proceed along the shear slip surface produced by the projectile jacket pressure on the target plate, which results in the circumferential scaly shear band in the perforation wall of target plate. Similarly, for $2 \mathrm{~A} 12$ aluminum alloy target plate with a thickness of $10 \mathrm{~mm}$, the angle between the cracks in the perforation wall of the target plate (near the front of the target plate) and the direction of the pressure produced by the projectile acting on the target is $57.23^{\circ}$. For the change of the direction of the cracks in the perforation wall, it is related to the decrease of the force of the projectile on the target plate and the change of the direction of the force.

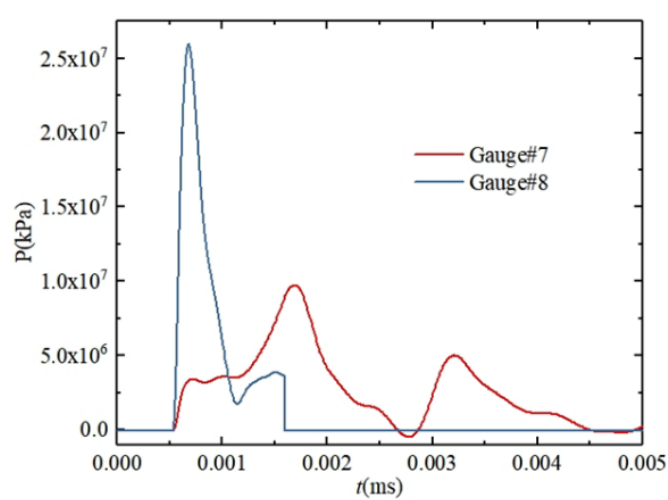

(a) $45 \#$ steel target plate $(5 \mathrm{~mm})$

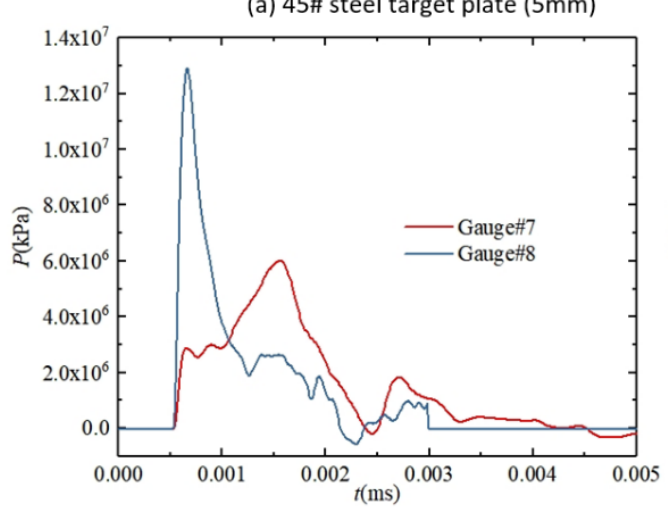

(c) 2 A12 aluminium alloy target plate $(5 \mathrm{~mm})$

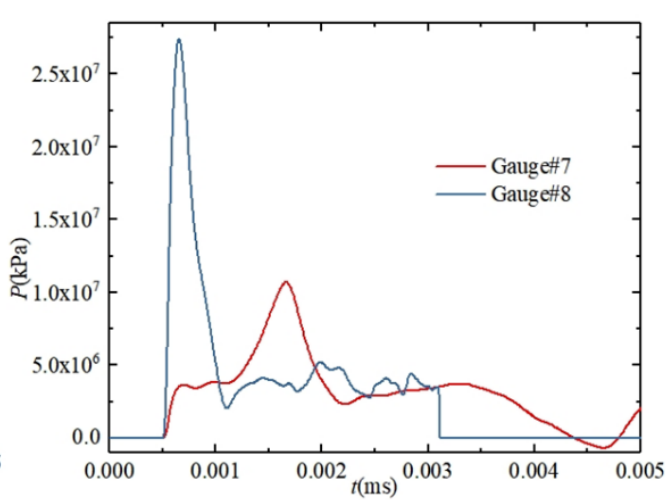

(b) $45 \#$ steel target plate $(10 \mathrm{~mm})$

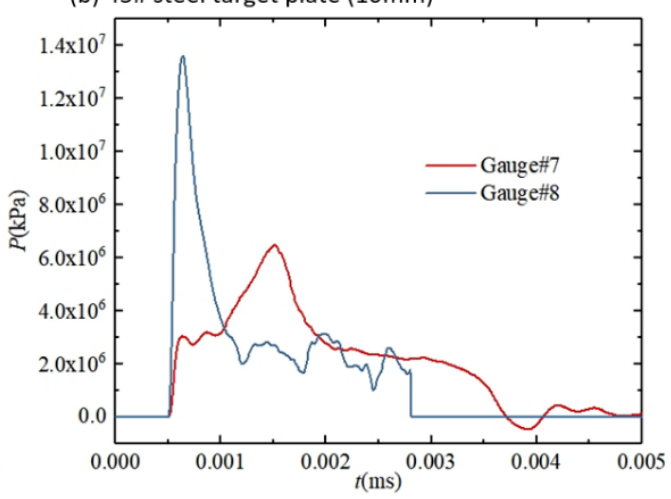

(d) 2 A12 aluminium alloy target plate $(10 \mathrm{~mm})$

Figure 11 Pressure at Gauge \#7 and Gauge \#8 

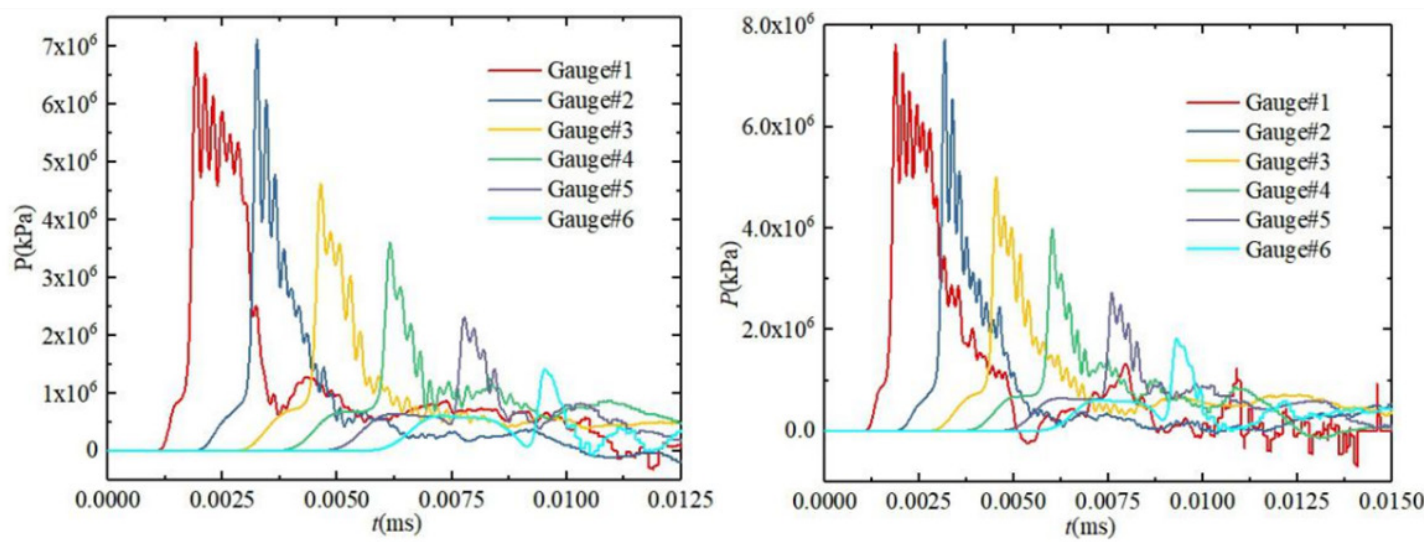

(a) $45 \#$ steel target plate $(5 \mathrm{~mm})$

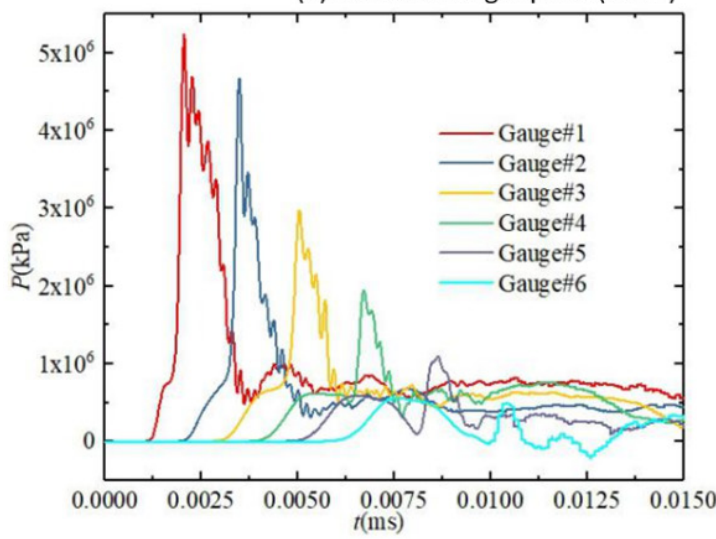

(b) $45 \#$ steel target plate $(10 \mathrm{~mm})$

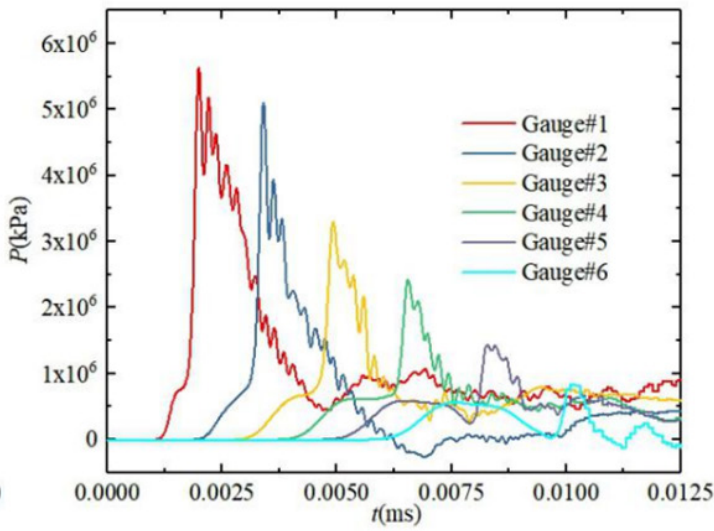

(c) $2 \mathrm{~A} 12$ aluminium alloy target plate $(5 \mathrm{~mm})$ (d) $2 \mathrm{~A} 12$ aluminium alloy target plate $(10 \mathrm{~mm})$

Figure 12 Pressure on the inner wall of the jacket at each observation points

\section{CONCLUSIONS}

In this paper, the experiment and simulation of 45\# steel target plates with $5 \mathrm{~mm}$ thickness and $10 \mathrm{~mm}$ thickness, and $2 \mathrm{~A} 12$ aluminum alloy target plates with $5 \mathrm{~mm}$ thickness and $10 \mathrm{~mm}$ thickness perforated by PELE were carried out. The shape and size of the perforations on the target plate and the plugs were analyzed. The distribution and trend of cracks in the perforation wall were observed by SEM and metallographic microscopy. The pressure of projectile jacket in the process of penetrating target plate was observed by numerical simulation. The direction of action of projectile jacket on target plate was further studied, and the mechanism of PELE on metal target plate was revealed. The conclusions are as follows.

1. The perforation failure of metal target plate by PELE is a new form, which is different from the ductile perforation by conical-nosed projectile and the punching failure by flat-nosed projectile.

2. For $45 \#$ steel plate, the perforation wall of the target plate is bright but uneven, the longitudinal cross section of the perforation is funnel-shaped, the diameter of the perforation on the back of the target plate is obviously larger than that on the front, and there are a lot of cracks in the perforation wall which are parallel to the perforation wall. For 2A12 aluminum alloy target plate, a large number of cracks are formed at the edge of the perforation wall, and the length of the cracks decreases gradually from the front to the back of the target plate.

3. The shape of the plug formed by 45 \# steel target plate and $2 \mathrm{~A} 12$ aluminum alloy target plate subjected to PELE is like a circular truncated cone, which is obviously different from the cylindrical plug formed form the metal target plate impacted by ordinary flat-nosed projectile.

4. Because the direction of the projectile acting on the target plate is different from that of the traditional flat-nosed projectile, funnel-shaped perforation and circular truncated cone shaped plug are formed for the 45 \# steel and 2A12 aluminum alloy target plate. 


\section{Acknowledgments:}

The work was supported by National Natural Science Foundation of China (Grant No. 11802141, 11802130).

Author's Contributions: Conceptualization, C Cheng, Z Du and X Chen; Methodology, C Cheng, Z Du and X Chen; Investigation, C Cheng, Z Du, X Chen and Z Pang; Writing - original draft, C Cheng, Z Du and X Chen; Writing - review \& editing, $X$ Chen and $Z$ Du; Formal analysis, $C$ Cheng, Meng Wang and $Y$ Sun; Funding acquisition, $X$ Chen and $Z$ Du; Project administration, $X$ Chen and $Z$ Pang; Software, C Cheng, LX X and Meng Wang; Supervision, $X$ Chen and $Z$ Du; Data curation, $C$ Cheng, $L X U$ and $Y$ Sun.

Editor: Marcílio Alves.

\section{References}

Arias, A., Rodríguez-Martínez, J. A., Rusinek, A. (2008). Numerical simulations of impact behaviour of thin steel plates subjected to cylindrical, conical and hemispherical non-deformable projectiles. Engineering Fracture Mechanics 75:1635-1656.

Børvik, T., Hopperstad, O. S., Langseth, M., et al. (2003). Effect of target thickness in blunt projectile penetration of Weldox 460 E steel plates. International Journal of Impact Engineering 28: 413-464.

Børvik, T., Hopperstad, O. S., Berstad, T., et al. (2002a). Perforation of $12 \mathrm{~mm}$ thick steel plates by $20 \mathrm{~mm}$ diameter projectiles with flat, hemispherical and conical noses: Part II: numerical simulations. International Journal of Impact Engineering 27:37-64.

Børvik, T., Langseth, M., Hopperstad, O. S., et al. (2002b). Perforation of $12 \mathrm{~mm}$ thick steel plates by $20 \mathrm{~mm}$ diameter projectiles with flat, hemispherical and conical noses: Part I: Experimental study. International Journal of Impact Engineering, 2002, 27:19-35.

Chen, X. W., Zhou, X. Q., Li, X. L. (2009). On perforation of ductile metallic plates by blunt rigid projectile. European Journal of Mechanics, A/Solids 28:273-283.

Cheng, C., Du, Z. H., Chen, X. et al. (2019). Simulation of fragmentation characteristics of projectile jacket made of tungsten alloy after penetrating metal target plate using SPH method. Defence Science Journal 69: 591-598.

Dey, S., Børvik, T., Hopperstad, O. S., et al. (2004). The effect of target strength on the perforation of steel plates using three different projectile nose shapes. International Journal of Impact Engineering 30:1005-1038.

Ding, L. L., Zhou, J. Y., Tang, W. H.,et al. (2018). Research on the Crushing Process of PELE Casing Material Based on the CrackSoftening Algorithm and Stochastic Failure Algorithm. Materials 11: 1-19.

Dolinski, M., Ritte, D. (2015). Experiments and modeling of ballistic penetration using an energy failure criterion. Journal of the Mechanics and Physics of Solids 83:1-18.

Fan, Z. J., Ran, X. W., Tang, W. H., et al. (2017). A study on fragmentation distribution of PELE. Journal of Vibration and shock 36: 72-77.

Goel, R., Kulkarni, M. D., Pandya, K. S., et al. (2014). Stress wave micro-macro attenuation in ceramic plates made of tiles during ballistic impact. International Journal of Mechanical Sciences 83:30-37.

Luo, R. M., Huang, D. W., Yang, M. C., et al. (2015). Research on Melted and Rapidly Solidified Layer on the Surface of Crater Penetrated by Long Tungsten Rod. Acta Armamentarii 48:1191-1200.

Masri R. (2015). Ballistically equivalent aluminium targets and the effect of hole slenderness ratio on ductile plate perforation. International Journal of Impact Engineering 80:45-55.

Paulus, G., Schirm, V. (2006). Impact behaviour of PELE projectiles perforating thin target plates. International Journal of Impact Engineering 33:566-579. 
Ramesh, K. T., Hogan, J. D., Kimberley, J., et al. (2015). A review of mechanisms and models for dynamic failure, strength, and fragmentation. Planetary and Space Science 107: 10-23.

Rodríguez-Martínez, J. A., Rusinek, A., Pesci, R., et al. (2013). Experimental and numerical analysis of the martensitic transformation in AISI 304 steel sheets subjected to perforation by conical and hemispherical projectiles. International Journal of Solids \& Structures 50: 339-351.

Tang, T.g., Li, Q. Z., Sun, X.L., et al. (2006). Strain-rate effects of expanding fracture of 45 steel cylinder jackets driven by detonation. Explosion Shock Waves 26: 129-133.

Jimmy, V. (2015). Analytical and numerical description of the PELE fragmentation upon impact with thin target plates. International Journal of Impact Engineering 76:196-206.

Zhu, J. S., Zhao, G. Z., Du, Z. H. (2009). Influence of Projectile Configuration on Functionary Effect of PELE. journal of system simulation 21: 39-42.

Zhu, J. S., Zhao, G. Z., Du, Z. H. (2010). Influence of the jacket material on PELE effect. Ordnance material science and Engineering 33: 14-16. 